\title{
JENIS-JENIS BELALANG ( Orthoptera: Ensifera ) PADA KAWASAN OBJEK WISATA AIR PANAS SAUMAN DESA RAMBAH TENGAH HULU KAB.ROKAN HULU
}

\author{
Refita Wiguna $^{1 *}$, Arief Anthonius Purnama ${ }^{1}$, Rena Lestari ${ }^{1}$

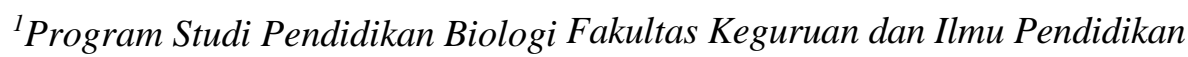 \\ Universitas Pasir Pengaraian \\ Jl. Tuanku Tambusai Kumu Desa Rambah Kecamatan Rambah Hilir. Pasir Pengaraian \\ *Email: Refitawigunaramanda@gmail.com
}

\begin{abstract}
This research aims to determine the species of grasshoppers (Orthoptera: Ensifera) located in Sauman hotsprings tourism object in the village of Rambah Tengah Hulu sub district of Rambah Rokan Hulu district. This study was conducted from December 2017 to March 2018 by survey method. Grasshopper obtained was then identified by describing the species based reference source. Result soft hestudy founda Grasshopper derived from 3 families, 7 subfamily, 8 genera and 10 species. As for the species of grasshoppers that Nisitrus vittatus, Teleogryllus emma, Teleogryllus sp., Conocephalus maculatus, Euconocephalus sp., Mecopoda sp., Mecopoda elongata, Phaneroptera brevis, Onomarchus uninotatus and Gryllotalpa nympichus.
\end{abstract}

Keywords: Species, Orthoptera, Ensifera.

\section{PENDAHULUAN}

Indonesia memiliki jumlah keanekaragaman hayati yang melimpah, serangga termasuk dalam jenis hewan dengan tingkat kepadatan yang tinggi karena memiliki lebih dari 25 ordo. Serangga hidup melimpah di lingkungan teresterial, udara dan perairan tawar namun jarang ditemukan dilautan. Seranga dapat berperan dalam proses penyerbukan tumbuhan, tetapi juga dapat merusak tanaman pertanian dan terlibat dalam penyebaran penyakit (Fried \& G.H. Hademenos, 2005). Belalang merupakan salah satu serangga yang sering dijumpai disetiap lingkungan. Belalang termasuk ke dalam ordo Orthoptera. Belalang sebagai serangga bersayap lurus. Belalang banyak dijumpai pada musim hujan dan musim panas (Anwar, 2013). Belalang hidup dengan jumlah yang melimpah pada daerah padang rumput dan sekitar $41 \%$ jenis belalang merupakan hewan pemakan rumput (Resh \& Carde, 2003b).
Secara umum, belalang dapat dibedakan menjadi 2 Sub Ordo yaitu Califera dan Ensifera. Califera mencakup semua belalang rumput (berantena pendek). Ensifera mencakup jangkrik, belalang berantena panjang dan belalang daun (Tan \& Kamaruddin, 2014). Pada Ordo Caelifera memiliki antena pendek, femur kaki belakang membesar, tarsus beruas 3 buah atau kurang, sedangkan pada Ensifera memiliki antena yang sama panjang dengan tubuhnya atau lebih panjang dari ukuran tubuhnya, tarsus ada yang beruas 3 buah, Ovipositor panjang dan ramping (Saskatchewan, Hadi, Tarwotjo, \& Rahadian, 2009). Di dalam subordo Ensifera terdapat 3 superfamili yaitu Gryllacridoidea, Tettigonioidea dan Gryllacridoidea (Gillot, 2005).

Ada beberapa jenis belalang yang terdapat di Indonesia yaitu: belalang kembara (Locusta migratoria), belalang daun (Phyllium fulchrifolium), belalang kayu (Valanga nigricornis), belalang sembah (Hierodula vitrea), belalang ranting (Phobaeticus chani), 
Wiguna, R., Purnama, AA., Lestari, R. 2018. Jenis-jenis Belalang (Orthoptera:Ensifera) pada Kawasan Objek Wisata Air Panas Sauman Desa Rambah Tengah Hulu. Sainstek : Jurnal Sains dan Teknologi. 10 (1) : 24-28

jangkrik (Gryllus mitratus) dan kecoa (Periplaneta Americana) (Erawati \& Kahono, 2010). Keanekaragaman dan kelimpahan belalang berhasil diidentifikasi lebih dari 20.000 spesies di dunia (Rentz, 2010).

Rokan Hulu merupakan salah satu Kabupaten yang ada di provinsi Riau dengan luas $7.449 .85 \mathrm{~km}^{2}$ yang memiliki banyak daerah yang berpotensi sebagai objek wisata. Daerah tersebut merupakan kawasan yang di tempati sebagai habitat hidupnya. Desa Rambah Tengah Hulu merupakan salah satu Desa yang memiliki objek wisata pemandian yang dimanfaatkan untuk terapi kesehatan antara lain: air Panas Sauman dan Hapanasan sehingga menjadi daya tarik masyarakat untuk datang berkunjung baik wisatawan dari dalam maupun luar kota. Objek wisata Air Panas Sauman merupakan salah satu tempat wisata yang banyak dikunjungi masyarakat dan memiliki keanekaragaman pepohonanan dan rerumputan seperti kelapa sawit, rumput ilalang, semak dan banyak berbagai macam bunga serta tumbuhan kecil lainnya yang merupakan habitat utama dari belalang (Orthoptera: Ensifera). Pada objek wisata Air Panas Sauman ini belum pernah dilakukan penelitian mengenai jenis-jenis belalang (Orthoptera: Ensifera) sehingga penting untuk dilakukan penelitian.

\section{METODE PENELITIAN}

Penelitian ini dilaksanakan pada bulan Desember 2017 sampai dengan Maret 2018. Pada Kawasan Objek Wisata Air Panas Sauman Desa Rambah Tengah Hulu Kabupaten Rokan Hulu. Penelitian ini dilakukan secara sengaja dengan pertimbangan tertentu pada sample (Purposive Sampling). Dilakukan pengambilan sampel pada setiap stasiun yang dianggap terdapat banyak belalang. Sebelum pengambilan sampel dilakukan, terlebih dahulu ditentukan titik koordinat menggunakan Global positioning System (GPS).
Sampel diambil pada setiap stasiun yang dianggap banyak terdapat belalang. Sesaat sebelum pengambilan sampel, terlebih dahulu menentukan titik koordinat dengan menggunakan GPS. Alat yang digunakan untuk mengambil sampel yaitu jaring serangga (insect net) pada 4 stasiun dalam 1 kawasan yang dilakukan 4 kali pengambilan pada masingmasing stasiun. Pengambilan sampel dimulai pada pukul $08.00-10.00 \mathrm{WIB}$, dilanjutkan pukul 14.30 - 16.30 WIB dan pukul $19.00-$ 20.30 WIB. Sampel yang ditemukan disimpan dalam termos yang berisi es batu agar sampel tidak rusak dan warnanya tidak berubah (Tan \& Kamaruddin, 2014)

Seluruh sampel yang didapatkan dibawa ke Laboratorium Biologi Program Studi Pendidikan Biologi Fakultas Keguruan dan Ilmu Pendidikan Universitas Pasir Pengaraian. Sampel diambil gambarnya demi mengamati karakter morfologi untuk identifikasi dengan menggunakan referensi Tan (2010) (Tan, 2011) (Tan, 2012) (Tan \& Wang., 2012)(Tan, R.W.J. Ngiam, Ibrahim, \& Ismail, 2013) tahap selanjutnya dilaksanakan proses pengawetan dan pengeringan sampel menggunakan cara menusuk toraks memakai jarum serangga serta diletakkan di atas papan perentang diberi jarum pentul untuk menata kaki agar kaki belakang dan depan sejajar dan disimpan di dalam oven dengan suhu $20-30{ }^{\circ} \mathrm{C}$ selama 3 hari. Setelah itu sampel disimpan dalam kotak spesimen dan diberi kapur barus.

\section{HASIL DAN PEMBAHASAN}

Berdasarkan hasil penelitian yang dilaksanakan di Desa Rambah Tengah Hulu pada Kawasan Objek Wisata Air Panas Sauman didapatkan 3 famili 7 sub famili 8 genus 10 spesies dan 238 individu untuk Orthoptera (Ensifera) dengan rincian di stasiun 1 berjumlah 25 individu, stasiun 2 berjumlah 56 individu, stasiun 3 berjumlah 77 individu dan stasiun 4 berjumlah 80 individu. 
Wiguna, R., Purnama, AA., Lestari, R. 2018. Jenis-jenis Belalang (Orthoptera:Ensifera) pada Kawasan Objek Wisata Air Panas Sauman Desa Rambah Tengah Hulu. Sainstek : Jurnal Sains dan Teknologi. 10 (1) : 24-28

Tabel 1. Spesies Ensifera (Insecta: Orthoptera) yang Didapatkan Selama Penelitian

\begin{tabular}{|c|c|c|c|c|c|c|c|c|}
\hline \multirow{2}{*}{ Subordo } & \multirow{2}{*}{ Famili } & \multirow{2}{*}{ Subfamili } & \multirow{2}{*}{ Spesies } & \multicolumn{4}{|c|}{ Stasiun } & \multirow{2}{*}{ Jumlah } \\
\hline & & & & 1 & 2 & 3 & 4 & \\
\hline \multirow{11}{*}{ Ensifera } & Gryllidae & Eneopterinae & Nisitrus vittatus & 0 & 6 & 3 & 6 & 15 \\
\hline & & Gryllinae & Teleogryllus sp. & 0 & 0 & 22 & 16 & 28 \\
\hline & & & Teleogryllus emma & 8 & 3 & 15 & 2 & 38 \\
\hline & Tettigoniidae & Conocephalinae & $\begin{array}{l}\text { Conocephalus } \\
\text { maculatus }\end{array}$ & 4 & 19 & 3 & 18 & 44 \\
\hline & & & Euconocephalus sp. & 8 & 3 & 0 & 0 & 11 \\
\hline & & Mecopodinae & Mecopoda sp. & 0 & 2 & 14 & 12 & 28 \\
\hline & & & Mecopoda elongata & 0 & 16 & 5 & 19 & 40 \\
\hline & & Phaneropterinae & Phaneroptera brevis & 5 & 4 & 12 & 6 & 27 \\
\hline & & Pseudophyllinae & $\begin{array}{l}\text { Onomarchus } \\
\text { uninotatus }\end{array}$ & 0 & 2 & 1 & 1 & 4 \\
\hline & Gryllotalpidae & Gryllotalpinae & $\begin{array}{l}\text { Gryllotalpa } \\
\text { nympichus }\end{array}$ & 0 & 1 & 2 & 0 & 3 \\
\hline & & Jumlah & & 25 & 56 & 77 & 80 & 238 \\
\hline
\end{tabular}

Berdasarkan Tabel 1, Jumlah individu banyak ditemukan di stasiun 2,3 dan 4 . Hal ini dikarenakan bentuk ekosistem padang rumput yang tinggi dan jenis rerumputan dan semak yang beranekaragam. Pada stasiun 1 jumlah individu spesies belalang yang didapatkan sangat sedikit karena habitat padang rumput yang rendah serta rumput-rumputan tidak beranekaragam sehingga menyebabkan spesies hanya sedikit ditemukan.

Jumlah spesies belalang yang paling banyak ditemukan selama penelitian adalah Conocephalus maculatus, Teleogryllus sp., Mecopoda elongata, Teleogryllus emma, Mecopoda sp. dan Phaneroptera brevis, sedangkan jumlah spesies belalang yang paling sedikit ditemukan adalah Nisitrus vittratus, Euconocephalus sp., Onomarchus uninotatus dan Gryllotalpa nympichus. Conocephalus maculates banyak ditemukan karena spesies ini merupakan salah satu spesies yang mampu hidup dengan berbagai macam bentuk vegetasi yang berbeda. Spesies yang paling sedikit didapat adalah Gryllotalpa nympichus karena hanya pada malam hari akan lebih banyak dijumpai ketika hari hujan dan spesies ini cenderung langka (lihat Gambar 1)

Umumnya spesies belalang yang banyak ditemukan bisa beradaptasi dengan habitat padang rumput yang berbeda-beda sehingga kemunculannya di alam melimpah. Sedangkan spesies belalang yang sedikit ditemukan karena jumlah dan kemunculan di alam yang tidak terlalau banyak, hanya mampu hidup pada habitat tertentu dan sebagian besar hanya aktif pada malam hari. Menurut Resh \& Carde, (2003) Orthoptera merupakan serangga terrestrial yang bisa hidup dimana saja diseluruh dunia kecuali dibagian terdingin permukaan bumi. Othoptera termasuk phytophilous (hidup pada daun-daunan), geophilous (hidup di gua-gua) dan myrmecophilous (hidup dengan semut). Orthoptera hidup pada habitat padang rumput dengan bentuk vagetasi yang macam-macam seperti kacang-kacangan dan tanaman lainnya. Dengan komunitas tumbuhan yang beranekaragam dengan sedikit semak belukar dan pepohonan yang tidak terlalu banyak. 
Wiguna, R., Purnama, AA., Lestari, R. 2018. Jenis-jenis Belalang (Orthoptera:Ensifera) pada Kawasan Objek Wisata Air Panas Sauman Desa Rambah Tengah Hulu. Sainstek : Jurnal Sains dan Teknologi. 10 (1) : 24-28

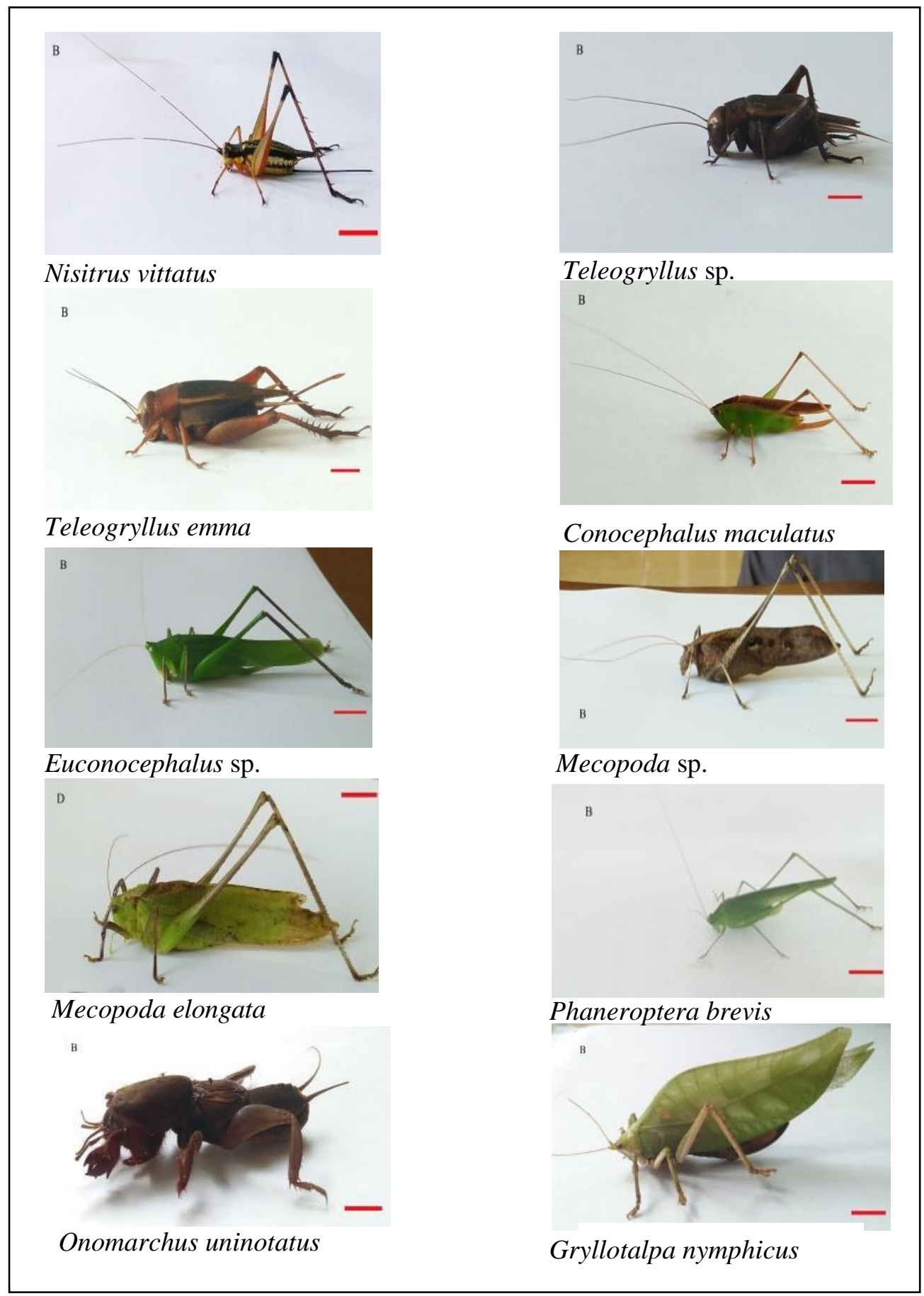

Gambar1. Spesies yang Ditemukan di Kawasan Objek Wisata Air Panas Sauman Desa Rambah Tengah Hulu Kabupaten Rokan Hulu. 
Wiguna, R., Purnama, AA., Lestari, R. 2018. Jenis-jenis Belalang (Orthoptera:Ensifera) pada Kawasan Objek Wisata Air Panas Sauman Desa Rambah Tengah Hulu. Sainstek : Jurnal Sains dan Teknologi. 10 (1) : 24-28

\section{KESIMPULAN}

Hasil penelitian menunjukan jenis-jenis belalang yang terdapat di Kawasan Objek Wisata Air Panas Sauman Desa Rambah Tengah Hulu Kabupaten Roka Hulu ditemukan 3 famili, 7 subfamili, 8 genus dan 10 spesies dengan jumlah individu 238. Adapun jenisjenis belalang yang didapat yaitu Nisitrus vittatus, Teleogryllus emma, Teleogryllus sp., Conocephalus maculatus, Euconocephalus sp.,Mecopodasp., Mecopoda elongata, Phaneroptera brevis, Onomarchus uninotatus dan Gryllotalpa nympichus yang diperoleh dari 4 stasiun penelitian.

\section{DAFTAR KEPUSTAKAAN}

Anwar, K. (2013). Biodiversity of Grasshoppers in Azad Nagar, Walgaon, Road. Amravati: International Journal of Latest Research in Science and Technology, 2(3), $10-12$.

Erawati, N. ., \& Kahono, S. (2010). Keanekaragaman dan Kelimpahan Belalang dan Kerabatnya (Orthoptera) pada Dua Ekosistem Pegunungan di Taman Nasional Gunung Halimun Salak. Jurnal Entomologi Indonesia, 2(2), 100115.

Fried, G. ., \& G.H.Hademenos. (2005). Schaum's Outlines BIOLOGI Edisi Kedua. Jakarta: Erlangga.

Gillot, C. (2005). Entomology Third Edition. Canada: University $O f$.
Rentz, D. (2010). A Guide to the Katydids of Australia. Australia: CSIRO Publishing.

Resh, V. ., \& Carde, R. T. (2003a). Elsevier Science (USA). ACADEMIC PRESS.

Resh, V. ., \& Carde, R. T. (2003b). Encyclopedia of Insects. Elsevier Science (USA). ACADEMIC PRESS.

Saskatchewan, Hadi, H. M., Tarwotjo, U., \& Rahadian, R. (2009). Biologi Insekta Entomologi. Yogyakarta:Grahallmu.

Tan, M. . (2010). Orthoptera of the Vacant Lots in Bedok South. Nature in Singapore, 6981.

Tan, M. . (2011). The Species of Asiophlugis.

Tan, M. . (2012). Orthoptera in The Bukit Timah and Central Catchment Nature Reservers (Part 2): Subordes Ensifera. Singapore: Raffles Museum of Biodiversity Research, National University Singapore.

Tan, M. ., \& Kamaruddin, K. M. (2014). Orthoptera of Fraser's Hill, Peninsular Malaysia. Singapore: Lee Kong Chian Natural History Museum National University of Singapore.

Tan, M. K., R.W.J. Ngiam, Ibrahim, M. R. B., \& Ismail. (2013). Diversity of Orthoptera From Neo Tiew Lane 2. Singapore. Nature in Singapore 6: 211-222.

Tan, M. K., \& Wang., L. K. (2012). The Orthoptera of Semakau Landfill. Singapore: A Project Semakau Checklist. Nature in Singapore 5: 309-318. 